\title{
Exploring Self-Efficacy as a Predictor of Disease Management
}

\author{
Noreen M. Clark, PhD \\ Julia A. Dodge, MS
}

\begin{abstract}
Self-efficacy is posited in social cognitive theory as fundamental to behavior change. Few health behavior studies have examined self-efficacy prospectively, viewed it as part of a reciprocal behavioral process, or compared self-efficacy beliefs in the same population across different behaviors. This article first discusses selfefficacy in its theoretical context and reviews the available prospective studies. Second, it explores self-efficacy as a predictor of disease management behaviors in 570 older women with heart disease. Although the $R^{2}$ statistics in each case were modest, the construct is shown to be a statistically significant $(p<.05)$ predictor at both 4 and 12 months postbaseline of several disease management behaviors: using medicine as prescribed, getting adequate exercise, managing stress, and following a recommended diet. Building self-efficacy is likely a reasonable starting point for interventions aiming to enhance heart disease management behaviors of mature female patients.
\end{abstract}

Self-efficacy is a construct of social learning theory that has been discussed in detail by Bandura $^{1}$ and examined in numerous studies (see, e.g., Lechner, de Vries, and Offermans $;{ }^{2}$ Moore, Turner, Park, and Adler ${ }^{3}$ ). Self-efficacy is the belief that one can carry out a behavior necessary to reach a desired goal, that is, achieve an expected outcome. This article first discusses the theoretical basis of self-efficacy as an element of disease management and then presents data from an exploratory study to examine the connections between self-efficacy beliefs and disease management behavior of older women with heart disease.

\section{SELF-EFFICACY IN THE CONTEXT OF SOCIAL COGNITIVE THEORY}

\section{Self-Efficacy in Self-Regulation}

Two important points about self-efficacy are made as it is discussed in social cognitive theory. ${ }^{1}$

Noreen M. Clark is Marshall H. Becker Professor of Public Health in the School of Public Health at the University of Michigan, Ann Arbor. Julia A. Dodge is a senior research associate in the School of Public Health at the University of Michigan, Ann Arbor.

Address reprint requests to Noreen M. Clark, University of Michigan School of Public Health, 109 Observatory Street, Ann Arbor, MI 48109-2029; phone: (734) 763-5454; fax: (734) 763-5455; e-mail: nmclark@umich.edu.

The work reported here was supported by grant 5 R01 HL38083 from the National Heart, Lung, and Blood Institute. The authors wish to thank Laura Spera and Jennifer Zakrajsek for their assistance in the preparation of this manuscript.

Health Education \& Behavior, Vol. 26 (1): $72-89$ (February 1999)

(C) 1999 by SOPHE 


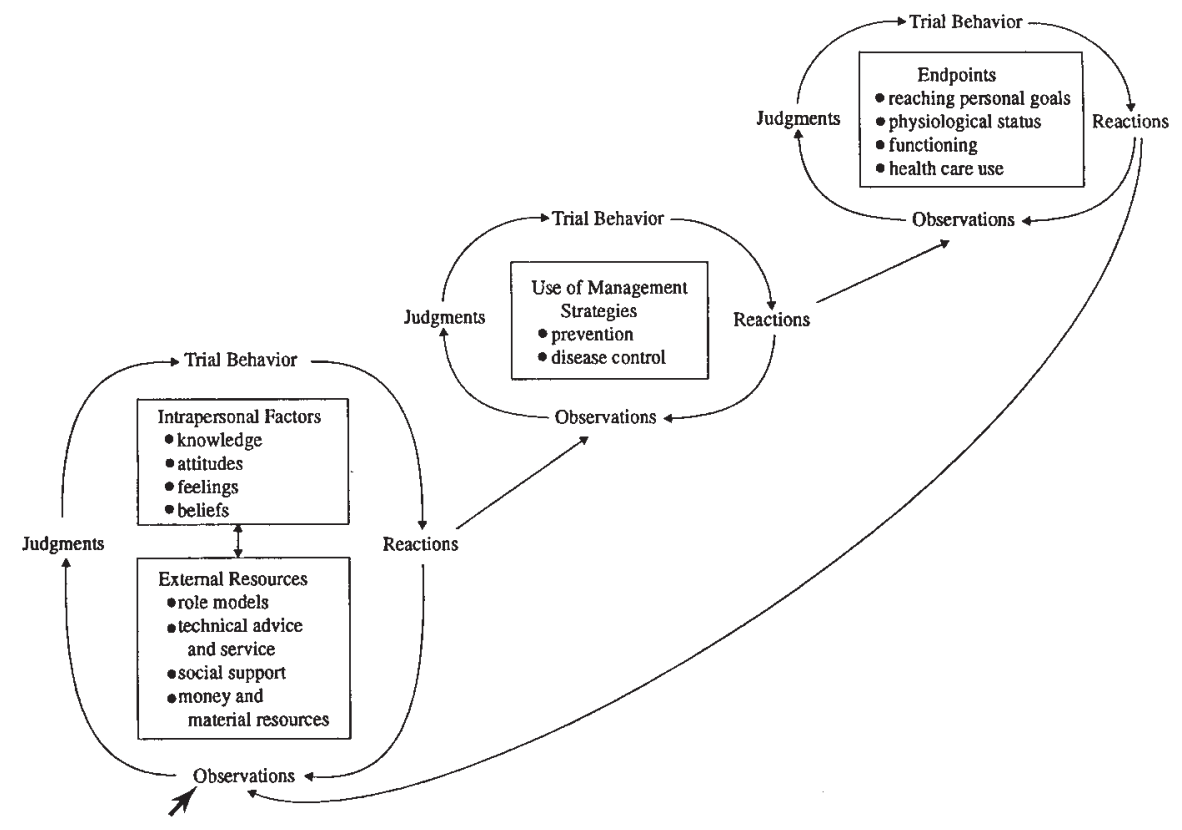

Figure 1. The continuous and reciprocal nature of the self-regulation in disease prevention and management.

\section{Self-Efficacy Is Part of a Process}

First is the idea that self-efficacy is part of a reciprocal process that determines behavior. Feelings of self-efficacy result from the interaction of personal, behavioral, and environmental factors (usually called triadic factors) ${ }^{4}$ that produce behavior. Self-efficacy is not independent from these triadic processes. Nonetheless, a large number of studies have treated self-efficacy in isolation without regard for how it fits into the more complex interplay of processes that lead us to behave as we do (for a review of health-related selfefficacy studies, see, e.g., Strecher, DeVellis, Becker, and Rosenstock; ${ }^{5}$ AbuSABHA and Achterberg $\left.{ }^{6}\right)$. Assessing the level of a person's self-efficacy gives important information but provides only a partial picture of how behavior is influenced.

Self-efficacy is a response to an attempt to achieve a goal. It is part of self-regulatory processes through which individuals shape environmental and intrapersonal resources and behavior toward a desired end. ${ }^{1}$ Clark and Zimmerman ${ }^{7}$ have delineated the specific components of self-regulation and applied them to disease management. Furthermore, Clark ${ }^{8}$ has presented a model of disease management that illustrates how self-efficacy fits into the reciprocal processes giving rise to disease management behavior. In this model, self-regulation is distinguished from management strategies one would employ to control a particular disease.

The model (see Figure 1) illustrates that individuals managing chronic disease wish to reach a personal goal or end point, for instance, sleeping through the night or engaging in a desired level of physical activity. One draws from intrapersonal resources (e.g., information, beliefs) and from external resources (e.g., advice from experts, role models) and engages in self-regulation, that is, one observes one's own behavior, makes judgments 
about it using a criterion (e.g., the behavior of a role model), tries out new behavior, and reacts to the experience, that is, draws conclusions from the trial. One reaction relates to outcome expectation. If the behavior produced the desired outcome, the behavior is more likely to be tried again. Another reaction is the feeling of self-efficacy, the belief in one's own capacity. If one judges oneself capable of once again carrying out the behavior that produced the wished-for result, one is confident, feels efficacious. The greater the selfefficacy, the greater the likelihood that the behavior will be repeated. Through these self-regulatory processes one identifies strategies that prove successful in preventing or controlling the effects of disease. In the model, these prevention or control strategies constitute disease management behavior

Social dimensions of the environment also influence self-regulated learning. Modeling or learning vicariously is a strong determinant of behavior. ${ }^{9}$ Self-regulating persons selectively expose themselves to models they think will help them function better. For example, smokers wishing to quit may choose to avoid their smoking cronies and ride to work in a car of nonsmokers. With regard to asthma, observing another asthma patient engage in a competitive sport, such as basketball, may motivate a fellow sufferer to overcome his fears and try to play also.

One sees in the model in Figure 1 that self-efficacy results from observing and judging the results of one's behavior as mediated by internal and external factors and employed in the effort to achieve a desired end point.

\section{Self-Efficacy Is Behavior Specific}

A second point made in theoretical discussions of self- efficacy is that it is not a trait or generalized response. It is very specific to a given behavior. One might feel very efficacious about taking a medicine as prescribed by the physician for management of heart disease and have no confidence at all that one can follow a dietary change the physician also recommends as part of the therapeutic plan. Self-efficacy varies with tasks and behavioral challenges. In this way it is unlike constructs, such as self-esteem, that describe a general state of being. Notwithstanding this theoretical assumption about self-efficacy, a number of studies (see, e.g., Long and Haney, ${ }^{10}$ Sherer et al. ${ }^{11}$ ) have tried to measure the amount of self-efficacy expressed by individuals about themselves in a general way. These efforts should likely not be construed as a true test of the construct.

Self-efficacy can both result from specific behavior and predict specific behavior. A true test of it requires a temporal ordering of data collection where the level of confidence of an individual to carry out a specific task or behavior is obtained and subsequent performance assessed, that is, a longitudinal design. Many extant studies of self-efficacy have employed cross-sectional data collection, most showing an association at a given point in time between self-efficacy and behavior but limited in predictive power. A few studies have observed initial self-efficacy and subsequent behavior. Table 1 presents findings from longitudinal research. ${ }^{2,3,12-24}$

Several observations can be made about self-efficacy as described in these findings. Self-efficacy has been shown to predict one's level of motivation to exercise and the intention to exercise. When it comes to actual behavior, results vary. When predicting exercise, it has worked well in one study, moderately well in another, and, in a third study, well for early exercise performance but not later performance. The construct has performed poorly in predicting smoking, interpersonal skills related to using condoms, and actual use of condoms. It has performed reasonably well in predicting sun safety behavior. As one would expect, self-efficacy is usually one of several factors (e.g., age, education)

Text continues on $p .78$ 
Table 1. Studies of Self-Efficacy Predicting Behavior (longitudinal data)

\begin{tabular}{|c|c|c|c|c|c|}
\hline Authors & Date & $N$ & Participants & Target Behavior & Results \\
\hline $\begin{array}{l}\text { Lechner, de Vries, } \\
\text { and Offermans }{ }^{2}\end{array}$ & 1997 & 395 & $\begin{array}{l}\text { Women who underwent an initial } \\
\text { screening in the Dutch National Breast } \\
\text { Cancer Screening Program }\end{array}$ & $\begin{array}{l}\text { Breast cancer } \\
\text { screening }\end{array}$ & $\begin{array}{l}\text { Participants in a second breast screening differed from } \\
\text { nonparticipants in all ASE (attitude, social influence, } \\
\text { efficacy) model determinants. }\end{array}$ \\
\hline $\begin{array}{l}\text { Moore, Turner, Park, } \\
\text { and Adler }{ }^{3}\end{array}$ & 1996 & 241 & Pregnant women 16 to 43 years old & $\begin{array}{l}\text { Smoking and } \\
\text { alcohol use }\end{array}$ & $\begin{array}{l}\text { Failed to find association between self-efficacy and } \\
\text { cigarette use; among smokers, drinking was related to } \\
\text { both drinking self-efficacy and previous drinking; } \\
\text { among nonsmokers, self-efficacy and beliefs about } \\
\text { consequences of drinking during pregnancy predicted } \\
\text { alcohol use. }\end{array}$ \\
\hline
\end{tabular}

Sorenson $^{12} \quad 1997 \quad 140 \quad$ Male and female middle-aged indi- $\quad$ Exercise viduals with elevated risk factors for ceived fitness, and exercise mastery explained $45 \%$ of cardiovascular disease who participated in exercise intervention 4 years earlier

Fontaine and $\quad 1997 \quad 109 \quad$ Obese individuals seeking outpatient treatment at a university-based weightmanagement center

the variance in self-rated motivation for exercise.

Weight loss

Weight Efficacy Lifestyle Questionnaire failed to correlate with either program attendance or weight loss.

Concluded that self-efficacy judgments are not predictive of short-term obesity treatment outcomes.

Forsyth and Carey $^{14} \quad 1997 \quad 43 \quad$ College-aged men Condom use

Condom Use Self-Efficacy Scale (CUSES) subscales relevant to negotiation of condom use did not account for significant variables in interpersonal skills:

CUSES subscale relevant to technical condom use skill did not account for variability in the condom application scores; caution against belief that higher self-efficacy reflects behavioral competence for HIV-

\section{ù} risk reduction. 
Table 1. Studies of Self-Efficacy Predicting Behavior (longitudinal data)

\begin{tabular}{|c|c|c|c|}
\hline Authors & Date & $N$ & Participants \\
\hline
\end{tabular}

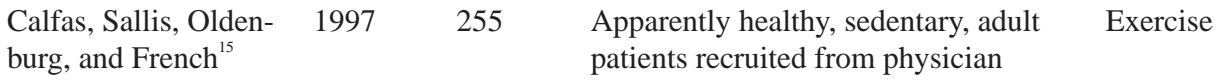

Bell and Alcalay ${ }^{16}$

Rodrigue $^{17}$

1996

Edmunson et al. ${ }^{18}$

\section{DuCharme and}

Brawley $^{19}$
55

Mothers of children aged 6 months to

10 years

1996

7,795

Third graders at intervention schools

Diet and

exercise

High- and low-acculturated Hispanic mothers in California

Wellness behavior

Avoiding sun

exposure

Healthy adult women enrolling for the Exercise first time at a women's fitness club
Assessments of physical activity at baseline and 4- to 6-week follow-up behavioral processes of change and self-efficacy made significant contributions to the multiple regression model explaining self-report and objective measures of physical activity.

Wellness Guide recipients had more enhanced assistance-seeking self-efficacy than nonrecipients. Low- and high-acculturated Hispanic mothers were equally likely to have made a change in behavior as a result of the guide.

Measured at baseline, 2 weeks postintervention, and 12 weeks postintervention: only those in the comprehensive intervention maintained sun-safe behaviors at 12 weeks; self-efficacy and response-efficacy influenced sun-safe behaviors.

Self-efficacy for dietary choices and physical activity increased moderately during third grade but declined during the last 2 years of the intervention; intermittent effects were observed for perceived support and selfefficacy for physical activity; moderate effects were maintained for knowledge, usual behavior, selfefficacy, and intention for health food choices.

Both efficacy to overcome barriers and efficacy for ability to schedule exercise predicted behavioral intention throughout the program; barrier efficacy was the best predictor during the first 2 months, while scheduling efficacy and past attendance were the strongest predictors during the last 2 months. 


\begin{tabular}{|c|c|c|c|c|c|}
\hline $\begin{array}{l}\text { McAuley, Courney, } \\
\text { Rudolph, and Lox }\end{array}$ & 1994 & 125 & $\begin{array}{l}\text { Middle-aged, sedentary, otherwise } \\
\text { healthy adults who responded to local } \\
\text { media advertising }\end{array}$ & Exercise & $\begin{array}{l}\text { Self-efficacy was a significant predictor of exercise } \\
\text { behavior in the early and middle stages of the 5-month } \\
\text { program but not during the last month; and not } \\
\text { through self-efficacy (contrary to hypothesis). }\end{array}$ \\
\hline $\begin{array}{l}\text { Winkleby, Flora, and } \\
\text { Kraemer }^{21}\end{array}$ & 1994 & 411 & $\begin{array}{l}\text { Adults } 25 \text { to } 74 \text { years old living in two } \\
\text { treatment cities who participated in } \\
\text { baseline and final cohort surveys }\end{array}$ & $\begin{array}{l}\text { Reduce CVD } \\
\text { risk }\end{array}$ & $\begin{array}{l}\text { Subgroup with lowest proportion of positive changers } \\
\text { had the lowest self-efficacy scores. }\end{array}$ \\
\hline Parker et al. ${ }^{22}$ & 1993 & 31 & $\begin{array}{l}\text { Male patients of a midwestern Virginia } \\
\text { hospital with diagnosis of classic or } \\
\text { definite rheumatoid arthritis }\end{array}$ & Pain behavior & $\begin{array}{l}\text { Pain behavior was more closely related to disease } \\
\text { activity than arthritis self-efficacy. }\end{array}$ \\
\hline Sharpe and Connell ${ }^{23}$ & 1992 & 250 & $\begin{array}{l}\text { Employees } 50 \text { to } 69 \text { years old who par- } \\
\text { ticipated in a large university- } \\
\text { supported health promotion trial }\end{array}$ & Exercise & $\begin{array}{l}\text { Self-efficacy was a predictor of intention to exercise at } \\
\text { baseline; however, after } 1 \text { year, baseline exercise fre- } \\
\text { quency was the only predictor of exercise behavior. }\end{array}$ \\
\hline $\begin{array}{l}\text { Sallis, Hovell, and } \\
\text { Hofstetter }^{24}\end{array}$ & 1992 & 1,719 & $\begin{array}{l}\text { Randomly selected men and women } \\
\text { who completed both baseline and } \\
\text { follow-up surveys }\end{array}$ & Exercise & $\begin{array}{l}\text { Adoption of vigorous activity by sedentary men was } \\
\text { predicted by self-efficacy, age (inverse), and neighbor- } \\
\text { hood environment (inverse); adoption of vigorous } \\
\text { activity by sedentary women was predicted by educa- } \\
\text { tion, self-efficacy, and friend/family support for exer- } \\
\text { cise. Maintenance was predicted by self-efficacy and } \\
\text { age (inverse) for initially active men. }\end{array}$ \\
\hline
\end{tabular}


predicting behavior. Its predictive ability varies with the type of behavior. Some behaviors, like smoking and using condoms, are often characterized by powerful inhibitors (e.g., addiction, desire for sexual spontaneity) that make it difficult to actually bring about change regardless of initial levels of confidence. Feelings of self-efficacy for some behaviors may be time bound and diminish with experience. For example, at the outset, getting exercise may seem an easy thing to do, but finding time, overcoming aches and pains, and so forth, may dilute behavior in the long term, making initial self-efficacy in some areas a poor marker of ultimate behavior.

\section{SELF-EFFICACY IN HEART DISEASE MANAGEMENT BY OLDER WOMEN}

Self-efficacy has not been studied extensively related to disease management in general or older adults in particular. However, it has been identified by several authors (see, e.g., Gill, Kelley, Williams, and Martin; ${ }^{25}$ Grembowski et al.$^{26}$ ) as a likely factor in the exercise behavior of older men and women. We had the opportunity to explore the role of self-efficacy in disease management in a sample of older women with heart disease and to consider three aspects of the construct. First, what factors were associated with self-efficacy beliefs in four specific areas of disease management: medicine use, diet, exercise, or stress management? Second, how were self-efficacy beliefs and outcome expectations correlated in relation to these specific heart disease management behaviors? Third, did self-efficacy beliefs predict behavior? While the available data did not enable an examination of all the assumed important influences discussed in social cognitive theory and outlined in the model presented here, they did comprise quite strong measures of at least two self-regulatory constructs of interest: self-efficacy and outcome expectation. Furthermore, as data were collected initially and subsequently at two follow-up periods, they allowed a reasonable exploration of the predictive ability of self-efficacy in heart disease management behaviors of older women.

\section{METHOD}

\section{Sample and Data Collection}

The 570 women providing data for this exploratory study were a noninstitutionalized, ambulatory population participating in a larger study of heart disease management. They were identified by a review of medical charts in outpatient clinics and physicians' offices affiliated with six large hospitals in southeastern Michigan and met the following criteria: female, 60 years of age or older, diagnosed cardiac disease, treated by daily heart medication, seen by a physician at least every 6 to 12 months, residing within 1 hour's drive of the study site, and willing and able to take part in an educational program and series of three telephone interviews conducted at baseline and 4 and 12 months later.

Potential study participants received an introductory letter explaining the research followed by a telephone call describing the study in more detail. All study participants were told that the purpose of the study was to learn more about what it is like for older women to live with a heart condition and to evaluate the effectiveness of self-management education. They were told that half of the participants would be randomly selected to attend a health education program. Furthermore, they were told that if they did not receive the 
program initially, they would have an opportunity to receive it at the end of the study if they were interested and if the program was shown to be beneficial. Five hundred seventy women consented to participate and provided baseline data. The primary reasons for not participating, given by those who were eligible but declined involvement, included time constraints, difficulties in traveling to the program site, and poor health. By the final follow-up period ( 12 months), data were available on 485 women, or $85 \%$ of the sample.

Those agreeing to take part in the study were assigned, by use of a table with random numbers, either to a "usual care" plus program group or a "usual care" control group. Usual care for a woman meant seeing her physician at the intervals specified by the particular clinician and receiving any information or education that would be provided as part of routine care in that setting. All study participants completed telephone interviews averaging 50 minutes in length. While the option of dividing interviews into two segments was offered to reduce respondent burden, most participants completed them in one telephone call. All interviewers were required to complete an extensive and in-depth training program that focused on standardizing the manner in which questions were asked, data recorded, and participant responses clarified. Performance of interviewers was monitored by a staff supervisor listening in at random on actual interviews, regular staff meetings, and supplemental training sessions. Individual participants were interviewed by different interviewers at the different time points, with the detailed training protocol assuring a standard approach to data collection.

The mean age of the women at baseline was 71.8 years with a range of 60 to 93 years. The majority (78\%) had graduated from high school, although 5\% had an eighth-grade or less education. Most respondents were retired from work outside the home; $11 \%$ were still employed full- or part-time. Fifty-one percent were currently married, while $35 \%$ were living alone. Eighty-seven percent were Caucasian. Participation by women of color was as follows: African American 11.6\%, Hispanic 0.7\%, Asian 0.4\%, and other 0.3\%. A variety of heart conditions were represented in the study population, including arrhythmia (59\%), angina (45\%), valve problems (25\%), and congestive heart failure (22\%). In addition, $67 \%$ of the participants had hypertension as well as another cardiac diagnosis. Thirty-nine percent of the sample reported a history of myocardial infarction, $26 \%$ had undergone bypass surgery, and $29 \%$ angioplasty. The length of time since the initial cardiac diagnosis ranged from a minimum of 6 months to 20 or more years. Sixty percent of the women considered the heart condition to be their primary health problem. When some other condition was named as a primary health problem, arthritis (21\%) was most often mentioned, followed by hypertension $(15 \%)$ and diabetes $(15 \%)$.

\section{Measures}

The study questionnaire comprised a series of items related to behavior in four areas included in the typical regimen for managing heart disease: medication use, modifying the diet, getting adequate exercise, and stress management. Items tapped specific constructs as follows:

- Self-efficacy. For each disease management area, the women's perceptions of their levels of self-efficacy related to that specific behavior were assessed by asking them, "On a scale of 1 to 10 where 1 is not at all confident and 10 is very confident, how confident are you that during the next month you can follow (for example) your exercise regimen?" 
- Outcome expectations. For each area, women were asked to indicate, using the same response scale, whether they believed following the regimen would benefit their health.

- Use of monitoring techniques. In each area, women were asked if they used a special technique(s) or system to monitor themselves (e.g., a reminder system for medicine taking).

- Behavior. Items in each disease management area assessed current behavior using the 10-point response scale. Medicine Use: On a scale of 1 to 10 where 1 is not very closely at all and 10 is very closely, how closely would you say you are following the doctor's instructions for taking your heart medication? Diet: On a scale of 1 to 10 where 1 is not very closely and 10 is very closely, how closely would you say you are following your diet(s)? Exercise: On a scale of 1 to 10 where 1 is not very closely at all and 10 is very closely, are you following an exercise or physical activity regimen? Stress: On a scale of 1 to 10 where 1 is not much effort at all and 10 is a lot of effort, how much effort would you say you make to lower the level of stress in your life? An objective measure, the Six-Minute Walk Test, ${ }^{27,28}$ was also used to assess behavior related to exercise. The aim was to determine the capacity of women to exercise in relation to their self-reports. The test, administered at a local hospital site by a nurse at a time approximating each follow-up interview, documented how far the participant could walk on a measured distance during a 6-minute time period.

Dimensions of physical and psychosocial functioning were assessed as follows:

- Functional status. Physical and psychosocial functioning were assessed by several standardized measures, including the 136-item Sickness Impact Profile, ${ }^{29}$ the Centers for Epidemiologic Studies Depression (CES-D) Scale, ${ }^{30,31}$ and the Medical Outcomes Study (MOS) Social Support Survey. ${ }^{32}$

- Symptom impact. Clinical status was assessed by calculating a symptom impact score using a 14-item Symptom and Health Profile developed by the authors. ${ }^{33}$

In addition, variables were added to further examine specific behaviors. For medication self-efficacy, the mean number of heart and nonheart medications being taken by the women was included. For self-efficacy to follow a recommended diet, additional variables were the woman's mean body weight, the distance she walked in the Six-Minute Walk, and whether a health professional had recommended the special diet. For exercise self-efficacy, whether the woman was currently exercising and whether her physician had recommended an exercise routine were also included. Finally, additional variables examined specifically for stress management self-efficacy were items to tap the woman's perceived level of stress during the past few months and whether a health professional had recommended stress reduction efforts.

The questionnaire contained additional variables of interest, including demographics, whether the heart condition was the primary health problem, the woman's perception of the seriousness of her heart condition, her rating of her present health, and the number of emergency room visits and hospitalizations in the previous 12 months.

\section{Data Analysis}

Three stages of analysis were undertaken. First, cross-sectional analysis was conducted to identify correlates of self-efficacy using baseline data. Second, associations 
between self-efficacy and outcome expectation were explored using longitudinal data. Third, the ability of self-efficacy to predict self-management behavior was examined using longitudinal data.

In the first stage of analysis, demographics — including age, race, educational level, whether a woman lived alone or with others, and her employment status-were used as independent variables in each of four regression models examining associations with self-efficacy in each area of disease management.

In the second stage of analysis demographic data and two self-regulation items, outcome expectation and self-efficacy at baseline, were examined, using multiple regression analysis, with outcome expectation at 4 and 12 months follow-up as the dependent variable. A separate regression model was run for each of the four areas of the heart disease management regimen. In the third stage, self-efficacy at baseline and demographic information were used to predict disease management behavior at 4 and 12 months follow-up, again using multiple regression analysis. As in the previous analysis stage, separate regression models were run for each of the four target areas. Subsequent stage 3 analyses also included baseline outcome expectation as an additional independent variable. Two additional independent variables were included in all second and third stage analyses: (1) a group indicator variable was added to control for the effects, if any, of the participation of some women in a heart disease health education program; and (2) a variable to indicate whether or not a technique was used by the women to help manage their heart condition.

\section{RESULTS}

\section{Correlates of Self-Efficacy}

As can be seen in Table 2, several factors were associated with the belief at baseline that one could follow dietary recommendations (diet self-efficacy). These were one's race (being of color), weight (lower weight), expectation that following the diet was beneficial (outcome expectation), and using a technique to monitor food intake. In this model, 19\% of the variance was explained. Variables correlated with baseline exercise self-efficacy were having fewer symptoms, one's positive outcome expectation, and whether one was currently exercising. This model explained $31 \%$ of the variance. For baseline stress management self-efficacy, $21 \%$ of the variance was explained by one's race, rating of better general health, and positive outcome expectation. The regression model examining selfefficacy in the area of medicine taking did not reach statistical significance, that is, it was unable to explain variability in baseline medication self-efficacy beliefs.

While several variables were significantly associated with baseline self-efficacy in each of the diet, exercise, and stress management models, only the variable regarding outcome expectation reached significance in all three. Higher outcome expectations were consistently associated with higher baseline self-efficacy scores.

\section{Associations Between Self-Efficacy and Outcome Expectation}

Table 3 illustrates relationships between baseline self-efficacy and subsequent outcome expectations. In all areas of disease management, baseline beliefs that the behavior would be beneficial to one's health predicted subsequent similar beliefs; that is, higher baseline expectations predicted higher follow-up expectations. This was true at 4 months 
Table 2. Relationship of Demographic Variables, Beliefs, and Behavior to Self-Efficacy for Diet, Exercise, and Stress Management at Baseline

\begin{tabular}{|c|c|c|c|}
\hline Variable & $\begin{array}{c}\text { Diet } \\
p \text { Value }\end{array}$ & $\begin{array}{l}\text { Exercise } \\
p \text { Value }\end{array}$ & $\begin{array}{c}\text { Stress Management } \\
p \text { Value }\end{array}$ \\
\hline Age & .31 & .79 & .17 \\
\hline Race & $.04 *$ & .08 & $.03 *$ \\
\hline Education: > high school & .89 & .48 & .38 \\
\hline Education: < high school & .94 & .90 & .27 \\
\hline Living alone & .10 & .77 & .32 \\
\hline Employed & .33 & .70 & .18 \\
\hline Heart condition primary problem & .39 & .34 & .81 \\
\hline Seriousness heart condition & .72 & .09 & .50 \\
\hline Symptom impact score & .49 & $.01 *$ & .65 \\
\hline CES-D ${ }^{\text {a }}$ depression score & .73 & .34 & .91 \\
\hline SIP $^{\mathrm{b}}$-physical dimension & .80 & .16 & .14 \\
\hline SIP-psychosocial dimension & .07 & .22 & .87 \\
\hline SIP-total score & .11 & .90 & .66 \\
\hline MOS $^{\mathrm{c}}$ social support score & .19 & .33 & .10 \\
\hline Rating present health & .26 & .35 & $.03 *$ \\
\hline Management skills compared others & .38 & .75 & .46 \\
\hline Emergency room visits past 12 months & .40 & .65 & .13 \\
\hline Hospitalizations past 12 months & .30 & .91 & .33 \\
\hline Weight & $.0001 *$ & .16 & - \\
\hline Distance walked in 6 minutes & .16 & .43 & - \\
\hline Currently exercising & - & $.004 * *$ & - \\
\hline Current level of stress & - & - & .15 \\
\hline Outcome expectation & $.03 *$ & $.0001 * *$ & $.002 *$ \\
\hline Use of technique & $.05^{*}$ & .29 & .11 \\
\hline Health provider recommended & .42 & .47 & 62 \\
\hline$R^{2}$ & .19 & .31 & .21 \\
\hline
\end{tabular}

a. CES-D = Centers for Epidemiologic Studies Depression Scale.

b. SIP = symptom impact score.

c. MOS = Medical Outcomes Study.

Significant by analysis of variance at $* p<.05$. ** $p<.01$.

postbaseline (medicine expectation parameter estimate $.326, S E .05, p=.0001$; diet expectation parameter estimate $.317, S E .05, p=.0001$; exercise expectation parameter estimate $.209, S E .64, p=.001$; stress reduction expectation parameter estimate .298 , $S E .06, p=.0001$ ). It was also true 1 year postbaseline (medicine expectation parameter estimate $.362, S E .05, p=.0001$; diet expectation parameter estimate $.305, S E .05, p=$ .0001 ; exercise expectation parameter estimate $.324, S E .07, p=.0001$; stress reduction expectation parameter estimate $.301, S E .06, p=.0001)$. In two areas, higher levels of baseline self-efficacy also predicted higher levels of follow-up outcome expectation. These were related to diet expectations at 4 months (parameter estimate $.050, S E .02, p=$ .03 ) and 12 months (parameter estimate $.074, S E .02, p=.002$ ) and to exercise expectation at 4 months (parameter estimate .082, $S E .02, p=.0001$ ) and 12 months (parameter estimate $.063, S E .03, p=.01$ ). In both of these areas, living alone predicted outcome expectations at 12 months, but in opposite directions (greater diet expectations parameter 
Table 3. Baseline Predictors of Subsequent Outcome Expectations

\begin{tabular}{|c|c|c|c|c|c|c|c|c|}
\hline \multirow[b]{2}{*}{ Baseline Variable } & \multicolumn{2}{|c|}{ Medicine Is Beneficial } & \multicolumn{2}{|c|}{ Diet Is Beneficial } & \multicolumn{2}{|c|}{ Exercise Is Beneficial } & \multicolumn{2}{|c|}{$\begin{array}{l}\text { Stress Management } \\
\text { Is Beneficial }\end{array}$} \\
\hline & At 4 Months & At 12 Months & At 4 Months & At 12 Months & At 4 Months & At 12 Months & At 4 Months & At 12 Months \\
\hline Self-efficacy & & & $\mathrm{X}$ & $\mathrm{X}$ & $X$ & $\mathrm{X}$ & & \\
\hline \multicolumn{9}{|l|}{ Age } \\
\hline \multicolumn{9}{|l|}{ Race } \\
\hline \multicolumn{9}{|l|}{ Education > high school } \\
\hline \multicolumn{9}{|c|}{ Education $<$ high school } \\
\hline Living alone & & & & $X$ & & $X$ & & \\
\hline \multicolumn{9}{|l|}{ Employed } \\
\hline Group effect ${ }^{\mathrm{a}}$ & $\mathrm{X}$ & & & & & & & \\
\hline \multicolumn{9}{|l|}{ Use of technique } \\
\hline Outcome expectation & $\mathrm{X}$ & $\mathrm{X}$ & $\mathrm{X}$ & $\mathrm{X}$ & $\mathrm{X}$ & $\mathrm{X}$ & $\mathrm{X}$ & $\mathrm{X}$ \\
\hline$R^{2}$ & .14 & .13 & .18 & .19 & .18 & .21 & .13 & .14 \\
\hline
\end{tabular}

NOTE: An X means the item was significant by multiple regression analysis at $p<.05$.

a. Participation in health education. 
estimate $-.210, S E .10, p=.03$; lower exercise expectation parameter estimate $-.281, S E$ $.11, p=.02)$. No other variables were influential in outcome expectation at either 4 or 12 months postbaseline. The $R^{2}$ accounted for in all analyses was relatively low, ranging from .13 to .21 .

\section{Self-Efficacy as a Predictor of Behavior}

Table 4 illustrates that baseline self-efficacy consistently predicted subsequent disease management behavior. The effect was apparent at 4 months for adherence, that is, following the medical regimen (parameter estimate $.221, S E .07, p=.002$ ), following dietary recommendations (parameter estimate $.345, S E .04, p=.0001$ ), exercising (parameter estimate $.388, S E .06, p=.0001$ ), and practicing stress reduction (parameter estimate $.161, S E .05, p=.001$ ). It was also apparent for each area at 12 months (medicine use parameter estimate $.809, S E .08, p=.0001$; diet parameter estimate $.493, S E .05, p=$ .0001 ; exercise parameter estimate $.415, S E .07, p=.0001$; stress reduction parameter estimate $.111, S E .06, p=.05$ ). Baseline outcome expectations played a limited role, predicting exercising at 4 months (parameter estimate $.663, S E .18, p=.0004$ ) and stress management behavior at both time periods ( 4 months parameter estimate $.271, S E .13, p=$ $.04 ; 12$ months parameter estimate $.496, S E .15, p=.001)$. Living alone predicted less adherence to prescribed medicine use at 4 months (parameter estimate- $.167, S E .08, p=.05$ ), less diet recommendation adherence at 12 months (parameter estimate-.441, SE .19, $p=.02$ ), and less exercising at 12 months (parameter estimate $-.780, S E .31, p=.01$ ). The same variable predicted more stress reduction efforts at 4 months (parameter estimate $.635, S E .26, p=.02$ ). At 4 months, race predicted medicine use adherence (parameter estimate .297, $S E .13, p=.03$ ) and stress reduction efforts (parameter estimate -.777, $S E .38, p=.04$ ), with minority participants reporting lower medication adherence and more stress management. Having a lower level of education also predicted more stress management effort at 4 months. Participating in health education had an effect at 12 months on the extent to which participants followed their heart medication regimens (parameter estimate .187, $S E .08, p=.02$ ). No other variables exerted influence. The $R^{2}$ accounted for in each analysis was modest and ranged from .07 to .30 . Table 5 shows that baseline self-efficacy predicted how far a woman could walk at 4 months as measured by the Six Minute Walk test, but not at 12 months. On the other hand, the outcome expectation that exercise is beneficial to health predicted walking performance at both the 4- and 12-month follow-up points. Age also predicted walking capacity at both time periods, with the younger women able to walk farther at follow-up.

\section{DISCUSSION}

The idea of the reciprocal influences of self-efficacy, outcome expectation, and behavior in disease management is supported in these data. The cross-sectional analysis using baseline data derived three separate models in which outcome expectations were associated with self-efficacy beliefs related to following a dietary plan, exercising, and managing stress. No significant model emerged for using medicines. This is not surprising, as a large number of studies over time have shown that compliance with medical regimens is not associated with any demographic or easily identifiable characteristics. These data suggest that the belief that one can use medicines as instructed, that is, the feeling of selfefficacy, is also not associated with specific personal characteristics of the patient. 
Table 4. Baseline Predictors of Disease Management Behavior Related to Medicine Use, Diet, Exercise, Stress Reduction

\begin{tabular}{|c|c|c|c|c|c|c|c|c|}
\hline \multirow[b]{2}{*}{ Baseline Variable } & \multicolumn{2}{|c|}{ Medicine Use } & \multicolumn{2}{|c|}{ Following Diet } & \multicolumn{2}{|c|}{ Exercising } & \multicolumn{2}{|c|}{ Stress Reduction } \\
\hline & At 4 Months & At 12 Months & At 4 Months & At 12 Months & At 4 Months & At 12 Months & At 4 Months & At 12 Months \\
\hline Self-efficacy & $X$ & $\mathrm{X}$ & $\mathrm{X}$ & $\mathrm{X}$ & $\mathrm{X}$ & $\mathrm{X}$ & $\mathrm{X}$ & $\mathrm{X}$ \\
\hline \multicolumn{9}{|l|}{ Age } \\
\hline Race & $X$ & & & & & & $\mathrm{X}$ & \\
\hline Education > high school & & & & & & & $\mathrm{X}$ & \\
\hline \multicolumn{9}{|l|}{ Education $<$ high school } \\
\hline Living alone & $\mathrm{X}$ & & & $\mathrm{X}$ & & $\mathrm{X}$ & $\mathrm{X}$ & \\
\hline \multicolumn{9}{|l|}{ Employed } \\
\hline Group effect ${ }^{\mathrm{a}}$ & & $\mathrm{X}$ & & & & & & \\
\hline \multicolumn{9}{|l|}{ Use of technique } \\
\hline Outcome expectation & & & & & & $\mathrm{X}$ & $X$ & $X$ \\
\hline$R^{2}$ & .07 & .24 & .17 & .27 & .30 & .20 & .18 & .15 \\
\hline
\end{tabular}

NOTE: An X means the item was significant by multiple regression analysis at $p<.05$.

a. Participation in health education. 
Table 5. Baseline Predictors of Six-Minute Walk Performance at 4- and 12-Months Follow-Up

\begin{tabular}{|c|c|c|c|c|c|c|}
\hline \multirow[b]{3}{*}{ Variable } & \multicolumn{3}{|c|}{ At 4 Months } & \multicolumn{3}{|c|}{ At 12 Months } \\
\hline & \multicolumn{3}{|l|}{ Parameter } & \multicolumn{3}{|c|}{ Parameter } \\
\hline & Estimate & $S E$ & $p$ & Estimate & $S E$ & $p$ \\
\hline Self-efficacy & 27 & 12 & $.02 *$ & 19 & 12 & .13 \\
\hline Age & -17 & 4 & $.0001 *$ & -14 & 5 & $.002 *$ \\
\hline Race & 44 & 92 & .63 & 98 & 93 & .29 \\
\hline Education > high school & 92 & 59 & .12 & 58 & 58 & .32 \\
\hline Education $<$ high school & -111 & 73 & .13 & -162 & 75 & $.03 *$ \\
\hline Living alone & -100 & 56 & .08 & 44 & 57 & .48 \\
\hline Employed & .20 & 95 & .99 & -21 & 89 & .82 \\
\hline Group effect $^{\mathrm{a}}$ & 41 & 51 & .42 & 32 & 51 & .53 \\
\hline Use of technique & -77 & 56 & .17 & -16 & 57 & .78 \\
\hline Baseline outcome & & & & & & \\
\hline Expectation & 81 & 33 & $.01 *$ & 77 & 34 & $.03 *$ \\
\hline$R^{2^{1}}$ & & & & & & \\
\hline
\end{tabular}

a. Participation in health education.

* Significant by multiple regression analysis at $p<.05$.

Perhaps given characteristics predict self-efficacy for certain other types of behaviors, for example, race for diet and stress management self-efficacy or being an exerciser for exercise self-efficacy. However, the data presented here are too preliminary for such a conclusion.

When self-efficacy was examined in longitudinal data as a predictor of outcome expectation, each of the overall models related to each behavior was significant. However, self-efficacy was significant only in the diet and exercise models (both at 4 and 12 months). Those women who at baseline had confidence in their own ability to stick to their diets or get adequate exercise were more likely at follow-up to believe the diet or getting exercise was beneficial to their health. Self-efficacy beliefs at baseline regarding medicine use and stress management did not predict follow-up outcome expectations. It may be that in the course of trying out these behaviors women felt no direct reward, to the degree that by the follow-up period they believed the behaviors were not particularly beneficial to them. In other words, over time they altered downward their view of benefit. In all areas of disease management (medicine use, following a diet, exercising, managing stress), believing at baseline that adopting such behavior was beneficial predicted the same belief at follow-up.

A clear pattern appeared when longitudinal data were used to examine self-efficacy as a predictor of behavior. In all four disease management areas, baseline confidence that one could carry out the specific behavior resulted in higher levels of the behavior at both the 4- and 12-month follow-up periods. In these data the early predictive ability of selfefficacy and later decline seen by McAuley, Courney, Rudolph, and Lox ${ }^{20}$ was not evident except regarding the Six Minute Walk Test where age and baseline outcome expectation were the significant predictors at 4- and 12-months follow-up. The Six Minute Walk Test, as noted, is a test of capacity, not frequency of exercising. It may be particularly sensitive to the natural decline in physical ability of older women over time. No other baseline variables, including outcome expectation, consistently predicted disease management. 
While the variance accounted for in these analyses was not great, the predictive role of self-efficacy in each area was clear and significant.

This study was exploratory in nature and, while offering the advantages of presenting data related to two theoretical constructs of interest and longitudinal data analysis, it was limited in several ways. It used data from a population of older women with heart disease who may or may not share characteristics with a more general population of patients with chronic disease. Only one aspect per area of disease management was surveyed, that is, the woman's perception regarding how closely she was following recommendations regarding medicine use, diet, exercising, and stress reduction. It may be that finer distinctions of behavior (e.g., using one type of medicine versus another type) may have generated different results. Furthermore, data were not available on a range of factors that might predict behavior; for example, the items shown in the model presented in addition to basic demographic information, self-efficacy, and outcome expectation. It may be that other variables not tested would have a more profound effect on disease management behavior. Nonetheless, the data are interesting in that there are only a few studies available using longitudinal data related to aspects of disease management. In addition, results are consistent with theoretical assumptions ${ }^{1}$ and previous research. ${ }^{15,20}$

Study findings suggest that while the self-regulatory constructs examined are reciprocal, self-efficacy may warrant particular attention as a starting point in interventions focused on exercise, stress management, diet, and medicine use. Self-efficacy is relatively easy to measure; therefore, program implementers or clinicians could assess without great difficulty the baseline self-efficacy beliefs of their participants or patients. Emphasis on building confidence specific to a given behavior as part of clinician-patient communication or as an element of an educational program may increase the likelihood of subsequent behavior occurring. Indeed, until further evidence is available to describe the most influential factors in behavior related to these domains of disease management by older women, self-efficacy may be the most promising to address. Of course, patients need skills and information to succeed in following clinical recommendations, but emphasis on developing confidence appears to be an important dimension of the education they receive. Even the difficult area of medicine use could be anticipated to a degree by initial self-efficacy beliefs.

\section{References}

1. Bandura A: Self-Efficacy: The Exercise of Control. New York, Freeman, 1997.

2. Lechner L, de Vries H, Offermans N: Participation in a breast cancer screening program: Influence of past behavior and determinants on future screening participation. Prev Med 26:473-482, 1997.

3. Moore PJ, Turner R, Park CL, Adler N: The impact of behavior and addiction on psychological models of cigarette and alcohol use during pregnancy. Addictive Behav 21(5):645-658, 1996.

4. Zimmerman B: A social cognitive view of self-regulated academic learning. J Educ Psychol 80:329-339, 1989.

5. Strecher VJ, DeVellis BM, Becker MH, Rosenstock IM: Role of self-efficacy in achieving health behavior change. Health Educ Qu 13(1):73-91, 1986.

6. AbuSABHA R, Achterberg C: Review of self-efficacy and locus of control for nutrition-and health-related behavior. J Am Diet Assoc 10(97):1122-1132, 1997.

7. Clark NM, Zimmerman BJ: A social cognitive view of self-regulated learning about health. Health Educ Q 5(3):371-379, 1990. 
8. Clark NM: Self-regulation and heart disease, in Gochman DS (ed.): Handbook of Health Behavior Research II: Provider Determinants. New York, Plenum, 1997, pp. 149-165

9. Rosenthal TL, Zimmerman BJ: Social Learning and Cognition. Academic Press, New York, 1978.

10. Long BC, Haney CJ: Coping strategies for working women: Aerobic exercise and relation interventions. Behav Ther 19:75-83, 1988.

11. Sherer M, Maddux JE, Mercandante B, Prentice-Dunn S, Jacobs B, Roger R: The self-efficacy scales for health related diet and exercise behaviors. Psychol Reports 51:663-671, 1982.

12. Sorenson M: Maintenance of exercise behavior for individuals at risk for cardiovascular disease. Perceptual and Motor Skills 85:867-880, 1997.

13. Fontaine KR, Cheskin LJ: Self-efficacy, attendance, and weight loss in obesity treatment. Addictive Behav 22(4):567-570, 1997.

14. Forsyth AD, Carey MP: Evaluation of the validity of the condom use self-efficacy scale (CUSES) in young men using two behavioral simulations. Health Psychol 16(2):175-178, 1997.

15. Calfas KJ, Sallis JF, Oldenburg B, French M: Mediators of change in physical activity following an intervention in primary care: PACE. Prev Med 26:297-304, 1997.

16. Bell RA, Alcalay R: The impact of the Wellness Guide/Guia on Hispanic women's well-beingrelated knowledge, efficacy beliefs, and behaviors: The mediating role of acculturation. Health Educ Behav 24(3):326-343, 1997.

17. Rodrigue JR: Promoting healthier behaviors, attitudes, and beliefs toward sun exposure in parents of young children. Journal of Consulting and Clinical Psychology 64(6):1431-1436, 1996.

18. Edmundson E, Parcel GS, Feldman HA, Elder J, Perry CL, Johnson CC, Williston BJ, Stone EJ, Yang M, Lytle L, Webber L: The effects of the child and adolescent trial for cardiovascular health up psychosocial determinants of diet and physical activity behavior. Preventive Medicine 25:442-454, 1996.

19. DuCharme KA, Brawley LR: Predicting the Intentions and Behavior of exercise initiates using two forms of self-efficacy. J Behav Med 18(5):479-497, 1995.

20. McAuley E, Courney KS, Rudolph DL, Lox CL: Enhancing exercise adherence in middle-aged males and females. Preventive Medicine 23:198-506, 1994.

21. Winkleby MA, Flora JA, Kraemer HC: A community-based heart disease intervention: Predictors of change. Am J Public Health 84(5):767-772, 1994.

22. Parker JC, Callahan CD, Smarr KL, McClure KW, Stucky-Ropp RC, Anderson SK, Walker SE: Relationship of pain behavior to disease activity and health status in rheumatoid arthritis. Arthritis Care Res 6(2):71-77, 1993.

23. Sharpe PA, Connell CM: Exercise beliefs and behaviors among older employees: A health promotion trail. The Gerontologist 32(4):444-449, 1992.

24. Sallis JF, Hovell MF, Hofstetter CR: Predictors of adoption and maintenance of vigorous physical activity in men and women. Prev Med 21:237-251, 1992.

25. Gill DL, Kelley BC, Williams K, Martin JJ: Relationship of self-efficacy and perceived wellbeing to physical activity and stair climbing in older adults. Research Quarterly for Exercise and Sport 65(4):367-371, 1994.

26. Grembowski D, Patrick D, Diehr P, Durham M, Beresford S, Kay E, Hecht J: Self-efficacy and health behavior among older adults. J Health Soc Behav 34:89-194, 1993.

27. Butland RJA, Pang J, Gross ER, Woodcock AA, Geddes DM: Two-, six-, and 12-minute walking tests in respiratory disease. BMJ 284:1607-1608, 1982.

28. Guyatt GH, Sullivan MJ, Thompson PJ, Fallen EL, Pugsley SO, Taylor DW, Berman LB: The six-minute walk: A new measure of exercise capacity in patients with chronic heart failure. Can Med Assoc J 132:919-923, 1985.

29. Bergner M, Bobbit R, Carter WB, Gilson BS: The Sickness Impact Profile: Development and final revision of a health status measure. Med Care 19:787-805, 1981.

30. Radloff LS: The CES-D Scale: A self-report regression scale for research in the general population. Applied Psychosocial Measures 1(3):385-401, 1977. 
31. Krause N: Stress, alcohol use, and depressive symptoms in later life. The Gerontologist 35(3):296-307, 1995.

32. Sherbourne CD, Stewart AL: The MOS Social Support Survey. Soc Sci Med 32:705-714, 1991.

33. Clark NM, Janz NK, Dodge JA, Schork MA, Wheeler J, Liang J, Keteyian SJ, Santinga JT: Selfmanagement of heart disease by older adults: Assessment of an intervention based on social cognitive theory. Res Aging 19(3):362-382, 1997. 